\title{
A Case of Bilateral Occipital Lobe Infarcts Following Indian Tree Viper Bite
}

\author{
Rohan Mahale, Anish Mehta, Mahendra Javali, R. Srinivasa \\ Department of Neurology, M S Ramaiah Medical College \& Hospital, Karnataka, India
}

\section{Dear Sir:}

According to the World Health Organization (WHO), approximately 35,000 to 50,000 deaths are attributed to snakebites in India each year. Annually, more than 2,000,000 snakebites are reported in India. ${ }^{1}$ The leading cause of fatal snakebite in India is the Viperidae species consisting of Russell's viper (Daboia russelli) and saw scaled viper (Echis carinatus). ${ }^{2}$ Local cellulitis, renal failure, and systemic hemorrhage are the common clinical manifestations of a viper bite. ${ }^{2}$ Neurological sequelae due to cerebral infarction are rare, ${ }^{3}$ and there are few reports of posterior circulation ischemic infarction. ${ }^{4,5}$ Indian tree viper (Trimeresurus gramineus) is a venomous pit viper species found only in southern India. Herein, we report a case of posterior circulation infarct involving bilateral occipital lobe following Indian tree viper bite.

A 58-year-old otherwise healthy man, an agricultural worker native to Coorg district, Karnataka, was bitten by a snake on the right foot while working in the field. The snake was identified as Indian tree viper as per the descriptions given by the patient and his relatives. He had mild pain at the site of the bite and was on native medicines. On the third day following the snakebite, the patient developed sudden diminution of vision in both eyes. There was no history of redness, pain, or discharge in both eyes. He was alert and did not show limb weakness. He did not deny his diminution of vision in both eyes. He visited the local hospital and was referred to a larger hospital for further evaluation after 2 weeks. He received three vials of polyvalent anti-snake venom (ASV). At the time of admission, his pulse rate was 76 beats per minute, blood pressure was $130 / 82 \mathrm{mmHg}$, and respiratory rate was 22 cycles per minute. Local examination showed two fang marks with features suggestive of cellulitis on the dorsum of the right foot.

The patient was alert and oriented. Neurological examination was normal except for decreased visual acuity (right/left eye, $6 / 60$ by Snellen's visual acuity chart) with intact direct and consensual light reflexes. Fundus evaluation was normal. Laboratory results showed that hemoglobin was $12.2 \mathrm{gm} / \mathrm{dL}$, total leukocyte count was $16,500 / \mathrm{mm}^{3}$ with $70 \%$ neutrophils, and platelet count was $215,000 / \mathrm{mm}^{3}$. Liver and renal function tests, electrolytes, urine examination findings, and coagulation parameters were within normal limits. Electrocardiogram and chest radiogram were normal. Visual examination revealed bilateral homonymous hemianopia. Brain magnetic resonance imaging (MRI) showed hyperintensities on fluid attenuated inversion recovery (FLAIR) in both occipital lobes with restriction on diffusion-weighted imaging (DWI) (Figure 1A, B). Magnetic resonance angiography (MRA) revealed thinning of caliber of the basilar artery and both posterior cerebral arteries (PCA) (Figure 1C). 2D echocardiography and carotid and vertebral Doppler were normal.

He was treated with broad spectrum antibiotics, anti-platelets, nimodipine (60 mg every 6th hour), and anti-edema agents. During the 3 months of follow up, his visual acuity improved to 6/18 in both eyes. Follow-up MRA showed normalization of the caliber of the basilar artery and both PCAs (Figure 1D).

Cerebral ischemic infarction after viper bite is rare, ${ }^{2}$ and there are only a few case reports on the posterior circulation stroke. Cases of pontine infarct following Korean viper bite, ${ }^{5}$ fatal right occipital and bilateral cerebellar infarct following snakebite, ${ }^{6}$ occipital infarct following venomous pit viper (Bothrops lanceolatus) bite, ${ }^{7}$ and bilateral thalamic infarct following Russell's viper bite $^{8}$ have been reported. Subasinghe et al. reported a patient with blindness in both eyes following Russell's viper bite due to 

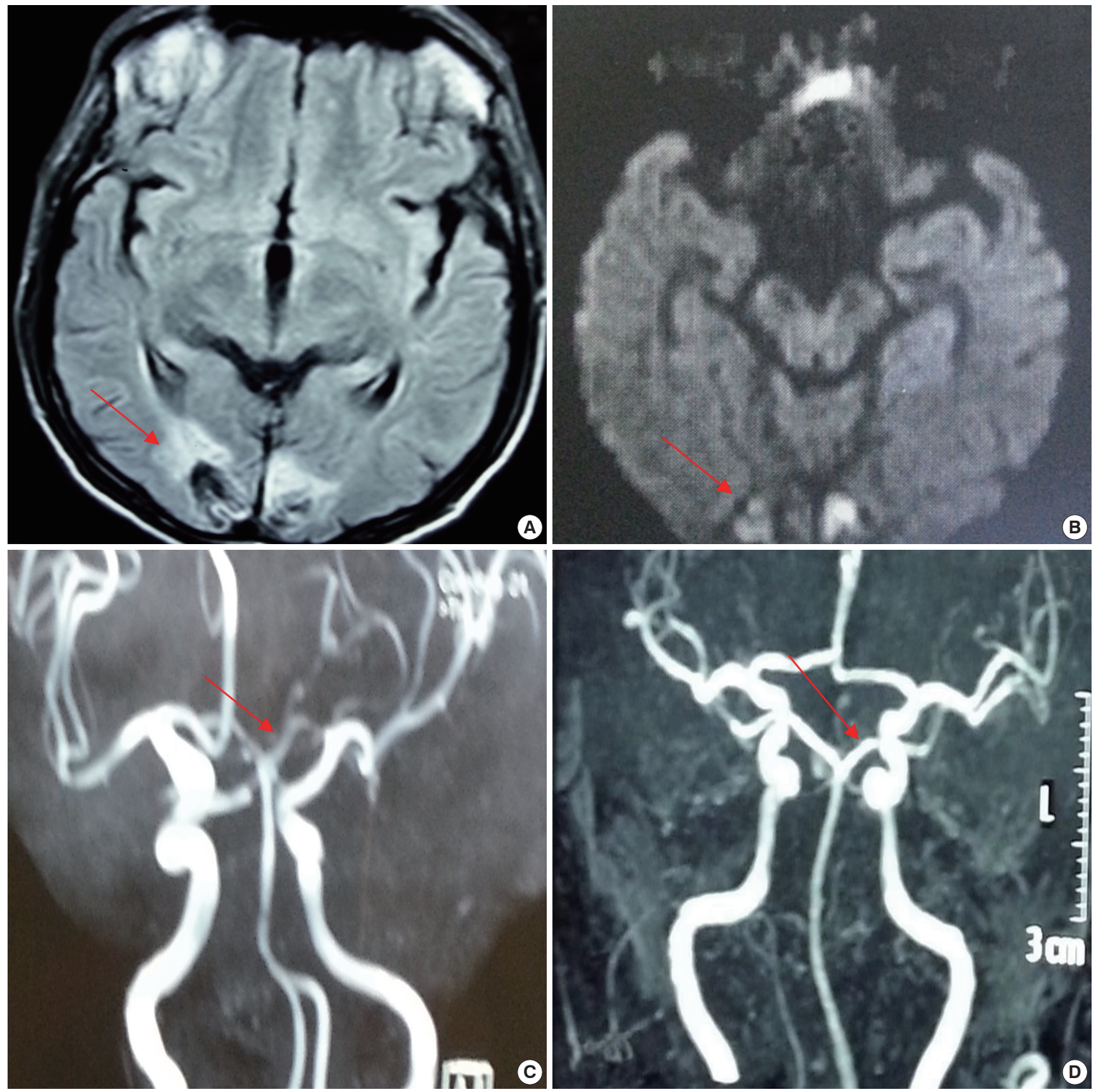

Figure 1. Brain magnetic resonance imaging (MRI): (A) Fluid attenuated inversion recovery (FLAIR) sequence axial view showing hyperintensity in bilateral occipital lobe (red arrow); (B) Diffusion-weighted imaging (DWI) showing hyperintensity in bilateral occipital lobe (red arrow); (C) Brain magnetic resonance angiography (MRA) showing thinning of caliber of basilar artery and both posterior cerebral artery (PCA) (red arrow); (D) Repeated MRA after 3 months showing normalization of caliber of basilar artery and both PCA (red arrow).

bilateral occipital lobe infarct. ${ }^{3}$ The postulate for the infarct as per authors was a probable generalized procoagulant effect of snake venom causing thrombosis of multiple large vessels. Angiographic evidence for the same was lacking in the study. Similarly, Gouda et al. reported a case of bilateral cerebellum and occipital lobe infarct following Russell's viper bite secondary to disseminated intravascular coagulation. ${ }^{4}$ Vale et al., reported a young male patient with top-of-basilar-syndrome (infarct in left temporo-occipital lobe with pons and cerebellum) following rattlesnake bite. Toxin-induced vascular spasm or toxic vasculitis was the probable cause for the infarct. ${ }^{9}$ Angiography did not reveal any abnormality in these patients.

Our patient presented with diminution of vision in both eyes following Indian tree viper bite without any other signs of systemic envenomation. Cerebral infarction following Indian tree viper bite has not yet been reported. The venom of Indian tree 
viper contains phospholipase A2 and 5'-nucleotidase which inhibit platelet aggregation. Viper snake venom is a complex toxin affecting hemostatic mechanisms. They exhibit both anticoagulant and procoagulant effects. ${ }^{10}$ Venom in large doses causes massive intravascular coagulation, leading to occlusion of small and even large vessels, resulting in cerebral infarction. Hypotension due to toxin mediated vasodilation and loss of vasomotor tone may cause ischemic infarct. ${ }^{10}$ Hemorrhagins, the complement-mediated toxic components of Viperidae snake venom, result in severe vascular spasm, endothelial damage contributing to vascular occlusion, and ischemic infarction.

In our case, cerebral infarction occurred without any coagulation or platelet abnormalities. MRA revealed decrease in calibre of the distal basilar artery and both PCAs that normalized after 3 months, suggesting toxin-mediated vasospasm. Partial thrombosis of the basilar artery, causing reduced blood flow with recanalization during repeat angiography, is also a possibility. This is the first case report describing bilateral occipital lobe infarcts following Indian tree viper bite probably due to toxin-mediated vasospasm.

\section{References}

1. WHO/SEARO. Guidelines for the clinical management of snake bites in the Southeast Asian region. Southeast Asian J Trop Med Publ Health 1999;30:1-85.

2. Narang SK, Paleti S, Azeez Asad MA, Samina T. Acute ischemic infarct in the middle cerebral artery territory following a Russell's viper bite. Neurol India 2009;57:479-480.

3. Subasinghe CJ, Sarathchandra C, Kandeepan T, Kulatunga A. Bilateral blindness following Russell's viper bite - a rare clinical presentation: a case report. J Med Case Rep 2014;8:99.

4. Gouda S, Pandit V, Seshadri S, Valsalan R, Vikas M. Posterior circulation ischaemic stroke following Russell's viper envenomation. Ann Indian Acad Neurol 2011;14:301-303.

5. Lee BC, Hwang SH, Bae JC, Kwon SB. Brainstem infarction following Korean viper bite. Neurology 2001;56:1244-1245.

6. Mugundhan K, Thruvarutchelvan K, Sivakumar S. Posterior circulation stroke in a young male following snake bite. J Assoc Physicians India 2008;56:713-714.

7. Merle H, Donnio A, Ayeboua L, Plumelle Y, Smadja D, Thomas L. Occipital infarction revealed by quadranopsia following snakebite by Bothrops lanceolatus. Am J Trop Med Hyg 2005; 73:583-585.

8. Ittyachen AM, Jose MB. Thalamic infarction following a Russell's viper bite. Southeast Asian J Trop Med Public Health 2012; 43:1201-1204.

9. Vale TC, Leite AF, Hora PR, Coury MI, Silva RC, Teixeira AL. Bilateral posterior circulation stroke secondary to a crotalid envenomation: case report. Rev Soc Bras Med Trop 2013;46:255256.

10. Boviatsis EJ, Kouyialis AT, Papatheodorou G, Gavra M, Korfias S, Sakas DE. Multiple hemorrhagic brain infarcts after viper envenomation. Am J Trop Med Hyg 2003;68:253-257.

Correspondence: Rohan R. Mahale

Department of Neurology, MS Ramaiah Medical College \& Hospital, Bangalore-560054, Karnataka, India

Tel: +91-80-40503125, +91-80-40503189

Fax: 080-2218 3276

E-mail: rohanmahale83@gmail.com

Received: April 28, 2014

Revised: July 2, 2014

Accepted: July 3, 2014

The authors have no financial conflicts of interest. 